\title{
Insulin response of the glucose and fatty acid metabolism in dry dairy cows across a range of body condition scores
}

\author{
J. De Koster, ${ }^{* 1}$ M. Hostens, ${ }^{*}$ M. Van Eetvelde, ${ }^{*}$ K. Hermans, ${ }^{*}$ S. Moerman, ${ }^{*}$ H. Bogaert, ${ }^{*}$ E. Depreester, ${ }^{*}$ \\ W. Van den Broeck, $†$ and G. Opsomer* \\ *Department of Reproduction, Obstetrics and Herd Health, and \\ †Department of Morphology, Faculty of Veterinary Medicine, Ghent University, Salisburylaan 133, 9820 Merelbeke, Belgium
}

\begin{abstract}
The objective of the present research was to determine the insulin response of the glucose and fatty acid metabolism in dry dairy cows with a variable body condition score (BCS). Ten pregnant Holstein Friesian dairy cows (upcoming parity 2 to 5 ) were selected based on BCS at the beginning of the study (2 mo before expected parturition date). During the study, animals were monitored weekly for BCS and backfat thickness and in the last $2 \mathrm{wk}$, blood samples were taken for determination of serum nonesterified fatty acid (NEFA) concentration. Animals underwent a hyperinsulinemic euglycemic clamp test in the third week before the expected parturition date. The hyperinsulinemic euglycemic clamp test consisted of 4 consecutive insulin infusions with increasing insulin doses: $0.1,0.5,2$, and $5 \mathrm{mIU} / \mathrm{kg}$ per minute. For each insulin infusion period, a steady state was defined as a period of $30 \mathrm{~min}$ where no or minor changes of the glucose infusion were necessary to keep the blood glucose concentration constant and near basal levels. During the steady state, the glucose infusion rate [steady state glucose infusion rate (SSGIR) in $\mu \mathrm{mol} / \mathrm{kg}$ per minute] and NEFA concentration [steady state NEFA concentration (SSNEFA) in $\mathrm{mmol} / \mathrm{L}]$ were determined and reflect the insulin response of the glucose and fatty acid metabolism. Dose response curves were created based on the insulin concentrations during the steady state and the SSGIR or SSNEFA. The shape of the dose response curves is determined by the concentration of insulin needed to elicit the half maximal effect (EC50) and the maximal SSGIR or the minimal SSNEFA for the glucose or fatty acid metabolism, respectively. The maximal SSGIR was negatively associated with variables reflecting adiposity of the cows (BCS, backfat thickness, NEFA concentration during the dry period, and absolute weight of the
\end{abstract}

Received January 14, 2015.

Accepted March 28, 2015.

${ }^{1}$ Corresponding author: jenne.dekoster@ugent.be different adipose depots determined after euthanasia and dissection of the different depots), whereas the EC50 of the glucose metabolism was positively associated with these variables. These results reflect a decreased insulin sensitivity and a decreased insulin responsiveness of the glucose metabolism in overconditioned dry dairy cows. The minimal SSNEFA and the EC50 of the fatty acid metabolism were not associated with variables reflecting adiposity of the cows, meaning that the insulin response of the fatty acid metabolism was not associated with the level of fat accumulation in dry dairy cows. Additionally, within individual cows, the EC50 of the glucose metabolism was higher than the EC50 of the fatty acid metabolism, meaning that the response of the fatty acid metabolism occurs at lower insulin concentrations compared with the response of the glucose metabolism. It can be concluded that a negative association exists between the level of fat accumulation in pregnant dairy cows at the end of the dry period and the insulin response of the glucose metabolism.

Key words: dairy cow, insulin response, glucose metabolism, fatty acid metabolism

\section{INTRODUCTION}

Insulin is an important hormone in the metabolism of mammals, birds, reptiles, fish, and amphibians. The metabolic effect of insulin is regulated by 2 factors. First, the secretory capacity of the $\beta$ cells of the pancreas, which determine the amount of insulin circulating in the blood stream. Second, the binding of insulin to its receptor and the activation of the intracellular signaling cascade in the insulin-sensitive tissues, which determine the insulin response of a certain tissue. Insulin resistance is defined as a state where a normal concentration of insulin induces a reduced biological response in the insulin-sensitive tissues. If the maximal effect of insulin is decreased, this is known as decreased insulin responsiveness. If more insulin is needed to elicit the half maximal effect, this is known as decreased insulin sensitivity. Insulin resistance can be attributed to 
a decrease in insulin responsiveness, insulin sensitivity, or both (Kahn, 1978).

In most mammals, and in dairy cows as well, the end of pregnancy and the initiation of lactation are accompanied by a transient state of decreased insulin action at the level of the glucose metabolism. This homeorhetic adaptation serves as a mechanism to preserve sufficient glucose supply for the gravid uterus and the lactating mammary gland in support of the growing offspring (Bell and Bauman, 1997; De Koster and Opsomer, 2013). Whereas this transient state of decreased insulin action in the periparturient period is considered a normal physiological phenomenon, excessive derailment of insulin's action in peripheral tissues is known to contribute in several pathological disorders in both human and veterinary medicine.

In human medicine, insulin resistance is a central disorder in the metabolic syndrome, a term used to group several obesity associated disorders, such as type 2 diabetes mellitus, hypertension, and cardiovascular disease. In the development of the metabolic syndrome, the obese adipose tissue plays a detrimental role by the release of NEFA and the production of a variety of adipokines (Wajchenberg, 2000; Cornier et al., 2008). Similar to obesity in human medicine, overconditioning in dairy cows is an important risk factor for the development of metabolic, digestive, infectious, and reproductive problems in the immediate postpartum period (Morrow, 1976; Roche et al., 2013). The increased susceptibility toward a variety of diseases in overconditioned cows may be explained by excessive NEFA mobilization due to a more pronounced negative energy balance (Grummer et al., 2004). Additionally, the adipose tissue of overconditioned cows has an increased sensitivity toward lipolytic signals and a decreased sensitivity toward antilipolytic signals (Rukkwamsuk et al., 1998; 1999; Kokkonen et al., 2005). Although it has been suggested that impaired insulin action at the level of the glucose and FA metabolism is an important contributor in the excessive mobilization of NEFA in overconditioned cows and the development of periparturient problems (Holtenius et al., 2003; Holtenius and Holtenius, 2007; De Koster and Opsomer, 2013), clear evidence for impaired insulin action at the level of the glucose and FA metabolism in clinically healthy overconditioned dairy cows does not exist.

The present study was conducted in dairy cows selected based on BCS at the end of the dry period. The aim of the study was to determine the insulin response of the glucose and FA metabolism of dairy cows with a variable BCS using the hyperinsulinemic euglycemic clamp (HEC) test. Because of the importance of the visceral adipose tissue in the development of insulin resistance in humans (Wajchenberg, 2000), we deter- mined the amount of fat in the different adipose depots by dissection of adipose tissue from subcutaneous, abdominal, intrapelvic, and intrathoracal depots. Next, we aimed to determine the influence of the weight of the different adipose depots and the proportional distribution of adipose tissue on the insulin response of the glucose and FA metabolism.

\section{MATERIALS AND METHODS}

All experimental procedures were approved by the ethical committee of the Faculty of Veterinary Medicine (EC2010/149, Ghent University).

\section{Study Design}

Ten clinically healthy, pregnant Holstein Friesian dairy cows (upcoming parity 2 to 5 ) were studied from 2 mo before the expected parturition date. At the beginning of the study, animals were selected based on BCS according to the scale of Edmonson et al. (1989) to ensure an equal spread in BCS from normal conditioned $(2.5-3.5 ; \mathrm{n}=5)$ to overconditioned $(3.75-5 ; \mathrm{n}=$ $5)$. Animals were dried off approximately $7 \mathrm{wk}$ before the expected parturition date. Cows were housed at the farm and were transported to the Faculty of Veterinary Medicine (Ghent University) 1 mo before the expected parturition date to allow for environmental adaptation. During the dry period, animals were fed rations based on corn silage and grass hay or straw (Table 1). At the farm, cows were offered the lactation ration diluted with chopped straw (67:33 ratio on a DM basis) to allow for ad libitum intake without overfeeding. At the faculty, cows were offered grass hay for ad libitum intake and $6 \mathrm{~kg}$ of corn silage DM each day. From 2 mo before the expected parturition date until the end of the study, cows were weekly monitored for BCS and backfat thickness (BFT; Schröder and Staufenbiel, 2006) by the same person and blood samples were taken from the coccygeal vein. Serum samples of the last 2 wk before the HEC test were analyzed for NEFA concentration.

\section{Hyperinsulinemic Euglycemic Clamp Test}

Hyperinsulinemic euglycemic clamp tests were performed in the third week (16 to $20 \mathrm{~d}$ ) before expected parturition date, as described by Kusenda et al. (2013). The day before the HEC test, cows were weighed and catheters (Cavafix Certo 338-14G, B. Braun, Instrulife, Oostkamp, Belgium) were fitted into both jugular veins. Water and hay were always available and corn silage was withheld from the cows from $12 \mathrm{~h}$ before the HEC test until the end of the HEC test. 
Table 1. Ingredients and chemical composition of the rations at the farm and at the faculty

\begin{tabular}{lcc}
\hline Item & $\begin{array}{c}\text { At the } \\
\text { farm }\end{array}$ & $\begin{array}{c}\text { At the } \\
\text { faculty }\end{array}$ \\
\hline Ingredient (\%, DM basis) & & \\
Corn silage & 25.42 & 50 \\
Grass silage & 9.46 & - \\
Grass hay & 2.53 & 50 \\
Soybean meal & 1.52 & - \\
Canola meal & 6.17 & - \\
Corn meal & 2.62 & - \\
Wheat & 1.35 & - \\
Malt distillers grain & 3.54 & - \\
Beet pulp & 7.35 & - \\
Corn gluten feed & 6.59 & - \\
Rape straw & 33.45 & - \\
Chemical composition & & \\
DM (\%) & 43 & 43.5 \\
NE ${ }^{1}$ (Mcal/kg) & 1.29 & 1.44 \\
CP (\%) & 12 & 11.3 \\
NDF (\%) & 50.7 & 53.1 \\
ADF (\%) & 29.8 & 30.2 \\
ADL (\%) & 2.6 & 9.5 \\
Starch (\%) & 13.0 & 20.0 \\
Crude fat (\%) & 2.0 & 3.25 \\
Ash (\%) & 4.3 & 6.35 \\
\hline
\end{tabular}

${ }^{1}$ Net energy for lactation as estimated by NRC (2001).

Blood samples were obtained from the right jugular catheter. Three blood samples were collected with 10min intervals to determine basal glucose, NEFA, and insulin concentrations. Following assessment of basal blood glucose concentration, 4 consecutive insulin infusions were administered through the left jugular catheter at increasing doses of insulin: $0.1,0.5,2$, and $5 \mathrm{mIU} / \mathrm{kg}$ per minute [Actrapid $100 \mathrm{IU} / \mathrm{mL}$, human recombinant insulin (Novo Nordisk, Bagsvaerd, Denmark) diluted in $0.9 \% \mathrm{NaCl}$ (B. Braun, Nerum, Heusden-Zolder, Belgium)]. The speed of each insulin infusion was set at a constant rate of $1 \mathrm{~mL} / \mathrm{min}$ for $140 \mathrm{~min}$ using an infusion pump (REGLO Digital MS-2/6, Ismatec, Voor't Labo, Eeklo, Belgium). Potassium chloride (KCl, P9541, Sigma-Aldrich, Bornem, Belgium) was administered to the animals during the insulin infusions of 2 and $5 \mathrm{mIU} / \mathrm{kg}$ per minute at a speed of $1 \mathrm{mmol} / \mathrm{min}$ to avoid hypokalemia. At regular time intervals $(2.5$ or 5 $\mathrm{min})$, the blood glucose concentration was determined using a glucometer (Precision Xceed, Abbott Diabetes Care, Verdifarm, Beringen-Paal, Belgium). Based on the measured blood glucose concentration, the speed of a concomitant glucose infusion [30\% glucose (Eurovet, Verdifarm, Beringen-Paal, Belgium) through the left jugular catheter] was adapted to keep the blood glucose concentration near basal levels. At 90, 100, 110, 120, 130, and 140 min after the start of each insulin infusion, blood samples were taken for determination of NEFA and insulin. After the end of the last insulin infusion, the glucose infusion was continued until the animal required no exogenous glucose to maintain a normal blood glucose concentration.

The steady state (SS) was defined as a period of 30 min during the last $50 \mathrm{~min}$ of the infusion period where no or minor changes of the glucose infusion were necessary to keep the blood glucose concentration constant and near basal levels. Therefore, the coefficient of variation $(\mathbf{C V})$ of the glucose infusion rate (GIR) and blood glucose needed to be less than 10\%. During each SS, the steady state glucose infusion rate (SSGIR), the steady state insulin concentration (SSIC), and the steady state NEFA concentration (SSNEFA) were calculated as the average GIR, the average insulin concentration, and the average NEFA concentration during the SS period, respectively.

\section{Blood Analyses}

Blood glucose concentrations were determined using a glucometer (Precision Xceed, Abbott Diabetes Care) and the intra-assay CV was $7.8 \%$. Samples for insulin and NEFA determination were taken in gel-coated blood tubes (Vacutest, Novolab, Geraardsbergen, Belgium), centrifuged for $20 \mathrm{~min}\left(2,460 \times g, 7^{\circ} \mathrm{C}\right)$ within $2 \mathrm{~h}$, and stored at $-80^{\circ} \mathrm{C}$ until analysis. Serum insulin concentrations were determined at the Clinical Chemistry Laboratory of the University Hospital (Ghent, Belgium) using a human-specific insulin electrochemiluminiscent immunoassay (ECLIA, Roche, Basel, Switzerland), intra- and interassay CV were 1.1 and $6.0 \%$, respectively. Serum NEFA concentrations were determined in a commercial laboratory (Mediclab, Aalst, Belgium) using an enzymatic endpoint method; intra- and interassay CV were 1.0 and $1.1 \%$, respectively.

\section{Euthanasia and Adipose Tissue Dissection}

One week after the HEC test (10 to $13 \mathrm{~d}$ before expected parturition date), cows were euthanized at the Department of Morphology (Faculty of Veterinary Medicine, Ghent University). The day before euthanasia, live BW of the cows was determined using a large animal floor scale (Bascules Robbe NV, Torhout, Belgium). Cows were stunned with a captive bolt gun and exsanguinated by transecting the carotid arteries and the jugular veins. Immediately after euthanasia, adipose tissue was dissected, weighed, and subdivided in 4 depots: the subcutaneous, the abdominal, the intrapelvic, and the thoracal adipose depot. The subcutaneous adipose depot contains all the adipose tissue that is located subcutaneously at the back, the sternum, and at the tailbase (including the adipose tissue in the fossa ischiorectalis). The abdominal adipose depot contains all the adipose tissue that is located in the omentum 
majus, omentum minus, mesenterium, and the perirenal and retroperitoneal adipose tissue. The intrapelvic adipose depot contains all the adipose tissue that is located in the pelvic cavity. The thoracal adipose depot contains all the adipose tissue that is located at the inside of the ribs, the adipose tissue in the mediastinum, and the adipose tissue around the heart (including the adipose tissue in the coronary grooves).

\section{Statistical Analyses}

All statistical analyses were performed using SAS version 9.4 (SAS Institute Inc., Cary, NC). Descriptive statistics are expressed as mean \pm standard error of the mean unless otherwise indicated. Normality of the data and error terms of the models were checked using the Kolmogorov-Smirnov test $(P<0.01)$. One cow was excluded from the statistical analysis because SS conditions were not reached in 2 of the 4 insulin infusion periods of the HEC test. Significance and tendency were declared at $P<0.05$ and $0.05<P<0.1$ respectively.

BCS and BFT During the Dry Period. Body condition score and BFT during the dry period were modeled using the PROC MIXED function with cow as random factor and time points during the dry period as repeated measurements within cow. Significant differences between time points were checked using the Bonferroni adjustment for multiple comparisons.

Dose Response Curves of the Glucose Metabolism. During the HEC test, the SSGIR reflects the insulin response of the glucose metabolism. Because this response is measured at increasing insulin concentrations, the HEC test gives the possibility to create dose response curves between the SSGIR and the SSIC. For each individual animal, the SSGIR was plotted with the SSIC and dose response curves were fitted using the PROC NLIN function using the following equation (Motulsky and Christopoulos, 2004):

$$
\mathrm{SSGIR}=\frac{\max _{\text {glucose }}}{1+10^{\left(\log \mathrm{EC} 50_{\text {glucose }}-\log \mathrm{SSIC}\right)}} .
$$

The shape of the dose response curve is determined by 2 parameters: $\max _{\text {glucose }}$ being the maximal SSGIR at maximal SSIC and EC50 glucose being the insulin concentration needed to achieve the half maximal effect.

Dose Response Curves of the FA Metabolism. During the HEC test, the SSNEFA concentration reflects the insulin response of the FA metabolism. Because the basal NEFA concentration was different between animals, SSNEFA concentrations were expressed as a percentage of the basal NEFA concentration (\%NEFA) to be able to compare the response of the FA metabolism between different animals. The NEFA response is measured at increasing insulin concentrations during the HEC test, giving the possibility to create dose response curves between the \%NEFA and the SSIC. For each individual animal, the \%NEFA was plotted with the SSIC and dose response curves were fitted using the PROC NLIN function using the following equation (Motulsky and Christopoulos, 2004):

$$
\% \mathrm{NEFA}=\min _{\mathrm{NEFA}}+\frac{1-\min _{\mathrm{NEFA}}}{1+10^{\left(\log \mathrm{SSIC}-\log \mathrm{EC} 50_{\mathrm{NEFA}}\right)}} .
$$

The shape of the dose response curve is determined by 2 parameters: $\min _{\mathrm{NEFA}}$ being the minimal \%NEFA at maximal SSIC and EC50 $0_{\text {NEFA }}$ being the insulin concentration needed to achieve the half maximal effect.

Influence of Body Fatness on the Parameters Derived from the Dose Response Curves. The parameters derived from the individual dose response curves $\left(\max _{\text {glucose }}, \mathrm{EC} 50_{\text {glucose }}, \min _{\mathrm{NEFA}}, \mathrm{EC} 50_{\mathrm{NEFA}}\right)$ were used to explore the influence of body fatness on the insulin response of the glucose and FA metabolism. For use in the statistical models, average values of BCS, BFT, and NEFA during the dry period within individual animals were calculated. Because the different variables reflecting body fatness were highly correlated ( $\mathrm{r}>0.60)$, univariate regression models were built to avoid multicollinearity. Influences on the parameters of the glucose and FA metabolism were analyzed using a univariate regression model with $\max _{\text {glucose }}, \mathrm{EC} 50_{\text {glucose }}$, $\min _{\mathrm{NEFA}}$, EC50 $0_{\mathrm{NEFA}}$ as dependent variables; BCS, BFT, NEFA level during the dry period, and the absolute and proportional amount of the different adipose depots were independent variables.

Comparison of EC50 Between Glucose and FA Metabolism. The EC50 of the glucose and FA metabolism reflects the insulin concentration needed to achieve the half maximal effect of the glucose or FA metabolism. Because both values were determined within the same individual, it is possible to compare the EC50 of the glucose and the EC50 of the FA metabolism within individual cows. Therefore, a mixed linear model was created with EC50 as dependent variable, metabolic path (glucose or FA metabolism) as independent variable and cow as random factor.

\section{RESULTS}

\section{Animal Characteristics}

Animal characteristics during the dry period are given in Table 2. The average BCS of the experimental animals during the dry period was $3.85(\mathrm{SD}=0.67)$. Five 
Table 2. Animal characteristics during the dry period

\begin{tabular}{lcccc}
\hline Item & Mean & SD & Minimum & Maximum \\
\hline BCS $^{1}$ & 3.85 & 0.67 & 3.11 & 5.00 \\
BFT $^{2}(\mathrm{~cm})$ & 2.39 & 1.15 & 1.20 & 4.58 \\
NEFA $^{3}(\mathrm{mmol} / \mathrm{L})$ & 0.27 & 0.18 & 0.08 & 0.55 \\
\hline
\end{tabular}

${ }^{1}$ Individual BCS was calculated as the average BCS during the dry period.

${ }^{2} \mathrm{BFT}=$ backfat thickness; individual BFT was calculated as the average BFT during the dry period.

${ }^{3}$ Serum individual NEFA was calculated as the average serum NEFA concentration in the $2 \mathrm{wk}$ preceding the hyperinsulinemic euglycemic clamp test.

animals were overconditioned $(\mathrm{BCS}>3.75)$, whereas 4 animals had a normal BCS (BCS <3.75). The average $\mathrm{BFT}$ of the experimental animals during the dry period was $2.39 \mathrm{~cm}(\mathrm{SD}=1.15)$. The average dry period NEFA concentration in the 2 wk preceding the HEC test was $0.27 \mathrm{mmol} / \mathrm{L}(\mathrm{SD}=0.18)$. Cows with a high NEFA level had higher BCS $(\mathrm{r}=0.79 ; P<0.05)$ and higher BFT $(\mathrm{r}=0.83 ; P<0.01)$. Both BCS and BFT were not correlated with the basal insulin concentration at the start of the HEC test $(\mathrm{r}=0.33$ and $0.17 ; P=$ 0.38 and 0.66 for BCS and BFT, respectively).

\section{Adipose Depot Weight}

The BW of the cows the day before euthanasia ranged from 631 to $858 \mathrm{~kg}$. The weight of total body fat, the weight of the different fat depots, and proportional distribution of body fat in different adipose depots are given in Table 3 . The thinnest cow had only $29.62 \mathrm{~kg}$ of total body fat, whereas the fattest cow had $114.26 \mathrm{~kg}$ of total body fat, indicating a large variation in total body fat and weight of the adipose depots. However, the proportional distribution of adipose tissue among the different depots showed very little variation. The largest amount of body fat was localized in the abdominal cavity $(66.70 \%$ of the total body fat; SD $=3.38$ ), followed by the subcutaneous adipose tissue $(17.99 \%$; SD $=2.19)$, the adipose tissue in the thoracal cavity $(9.04 \%$; $\mathrm{SD}=1.75)$, and in the pelvic cavity $(6.27 \% ; \mathrm{SD}=1.17)$.

\section{Hyperinsulinemic Euglycemic Clamp Test}

Figure 1 depicts the changes in blood glucose, insulin and NEFA concentrations, and GIR during the HEC tests. Infusion of human insulin increased the circulating insulin concentration and decreased circulating NEFA concentrations. To maintain blood glucose values near basal concentrations, the concomitant glucose infusion was increased to reach a SS between 90 and 140 min after the start of the insulin infusion (Table 4).

\section{Parameters Derived from the Dose Response Curves of the Glucose and FA Metabolism}

Figure 2 depicts the average values of the SSGIR and SSIC of the experimental animals together with the fitted dose response curves. The dose response curve of the insulin response of the glucose metabolism is determined by the $\mathrm{EC} 50_{\text {glucose }}$ and the $\max _{\text {glucose }}$. In the present experiment, the average values of the EC50 $0_{\text {glucose }}$ and $\max _{\text {glucose }}$ were $76.41 \pm 4.46 \mu \mathrm{IU} / \mathrm{mL}$ and $18.51 \pm 0.42 \mu \mathrm{mol} / \mathrm{kg}$ per minute, respectively (Table $5)$. The max $_{\text {glucose }}$ was negatively associated with BCS,

Table 3. Body weight, weight of total body fat, and weight of the different adipose depots and the proportion of the weight of the different adipose depots

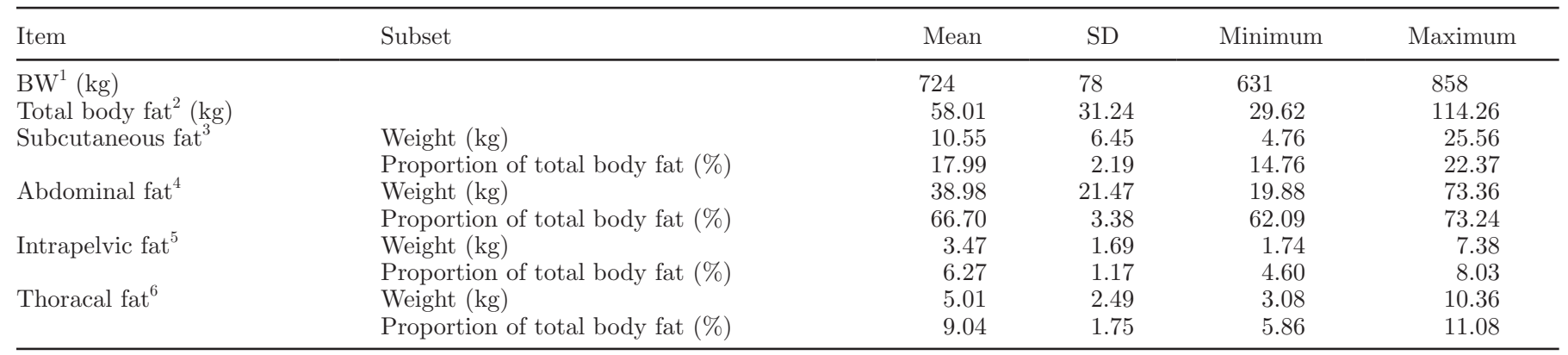

${ }^{1}$ Body weight determined the day before euthanasia.

${ }^{2}$ Total body fat is the sum of the abdominal, subcutaneous, intrapelvic, and thoracal fat.

${ }^{3}$ Subcutaneous fat contains all the dissected fat located subcutaneously at the back, the sternum, and the tailbase (including the fat in the fossa ischiorectalis).

${ }^{4}$ Abdominal fat contains all the dissected fat located in the omentum majus, omentum minus, mesenterium, and the perirenal and retroperitoneal fat.

${ }^{5}$ Intrapelvic fat contains all the dissected fat located in the pelvic cavity.

${ }^{6}$ Thoracal fat contains all the dissected fat located at the inner side of the ribs, the mediastinum, and around the heart. 

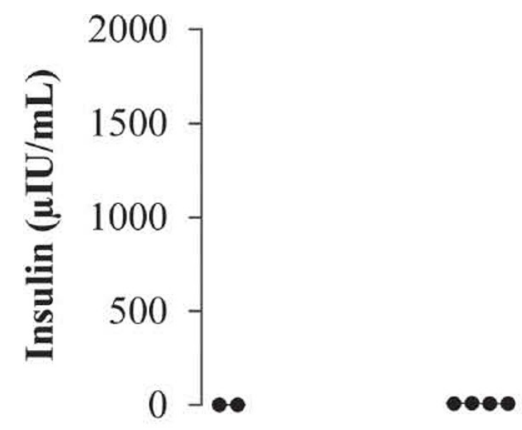

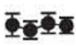

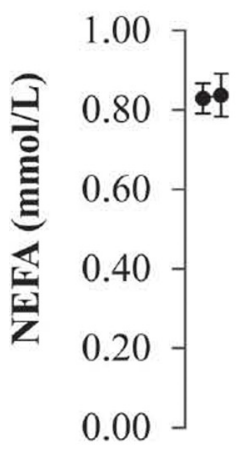

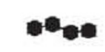

eare

$\bullet$
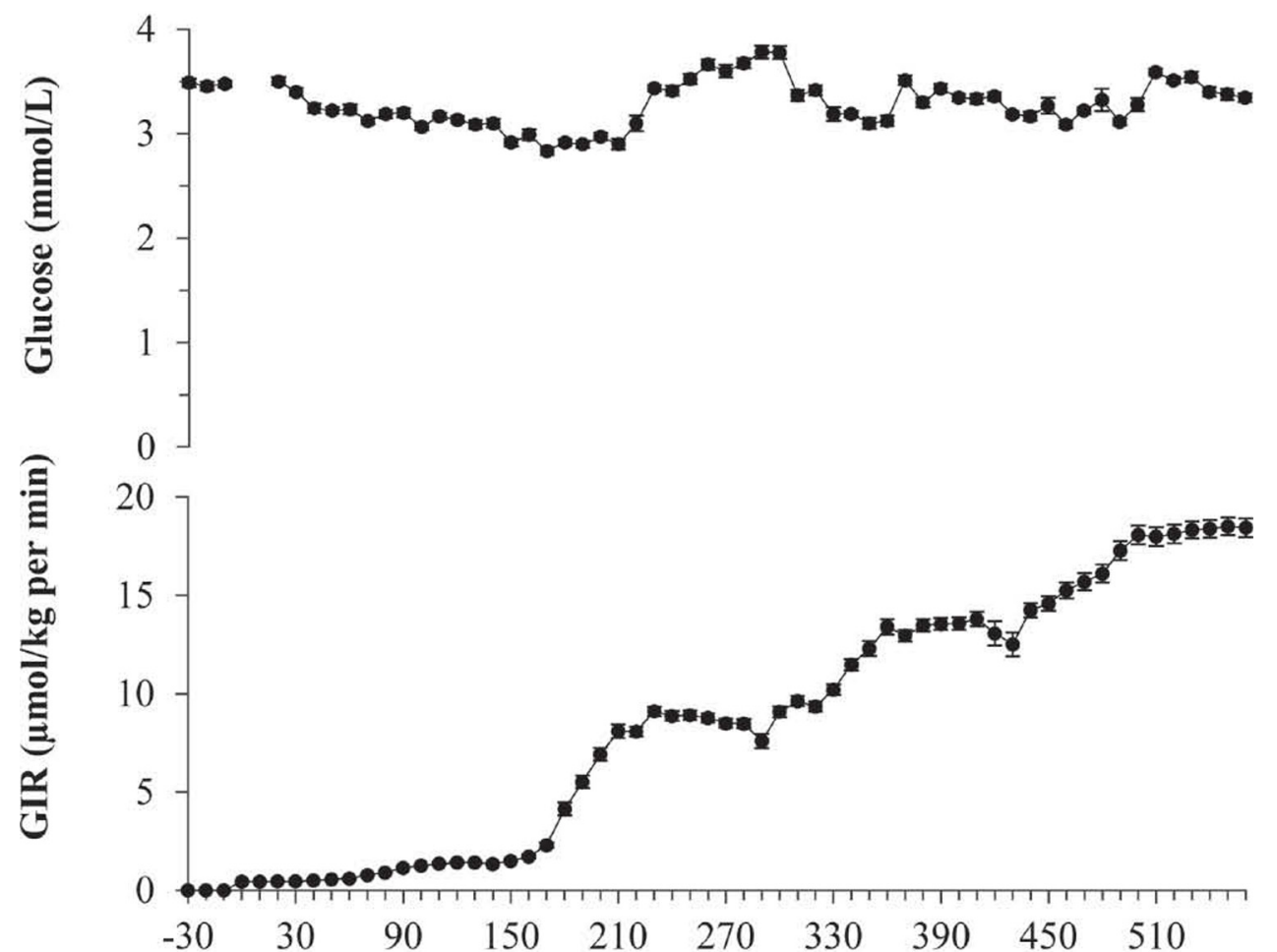

Time (min)

\begin{tabular}{|c|c|c|c|}
\hline 0.1 & 0.5 & 2 & 5 \\
$\mathrm{mIU} / \mathrm{kg}$ & $\mathrm{mIU} / \mathrm{kg}$ & $\mathrm{mIU} / \mathrm{kg}$ & $\mathrm{mIU} / \mathrm{kg}$ \\
per min & per min & per min & per min \\
\hline
\end{tabular}

Figure 1. Insulin, NEFA, and glucose concentration and glucose infusion rate (GIR) in the basal state and during the insulin infusion periods $(0.1,0.5,2$, and $5 \mathrm{mIU} / \mathrm{kg}$ per minute) of the hyperinsulinemic euglycemic clamp test. Points $(\bullet)$ represent the means, and error bars represent the SEM. 
Table 4. SSIC, ${ }^{1}$ SSGIR, ${ }^{2}$ SSNEFA,${ }^{3}$ and $\% \mathrm{NEFA}^{4}$ during the basal state and the different insulin infusion periods $^{5}$

\begin{tabular}{lcccc}
\hline Insulin infusion & $\begin{array}{c}\text { SSIC } \\
(\mu \mathrm{IU} / \mathrm{mL})\end{array}$ & $\begin{array}{c}\text { SSGIR } \\
(\mu \mathrm{mol} / \mathrm{kg} \text { per min })\end{array}$ & $\begin{array}{c}\text { SSNEFA } \\
(\mathrm{mmol} / \mathrm{L})\end{array}$ & $\%$ NEFA \\
\hline Basal state & $1.09 \pm 0.08$ & 0 & $0.83 \pm 0.05$ & 100 \\
$0.1 \mathrm{mIU} / \mathrm{kg}$ per minute & $8.52 \pm 0.33$ & $1.44 \pm 0.05$ & $0.58 \pm 0.02$ & $73.05 \pm 1.73$ \\
$0.5 \mathrm{mIU} / \mathrm{kg}$ per minute & $51.02 \pm 1.73$ & $8.77 \pm 0.28$ & $0.24 \pm 0.01$ & $29.50 \pm 1.41$ \\
$2 \mathrm{mIU} / \mathrm{kg}$ per minute & $337.24 \pm 12.70$ & $13.61 \pm 0.32$ & $0.13 \pm 0.01$ & $15.04 \pm 0.88$ \\
$5 \mathrm{mIU} / \mathrm{kg}$ per minute & $1,432.86 \pm 52.46$ & $18.33 \pm 0.45$ & $0.10 \pm 0.01$ & $12.07 \pm 0.57$ \\
\hline
\end{tabular}

${ }^{1}$ SSIC $=$ steady state insulin concentration.

${ }^{2} \mathrm{SSGIR}=$ steady state glucose infusion rate

${ }^{3} \mathrm{SSNEFA}=$ steady state NEFA concentration.

${ }^{4} \%$ NEFA calculated as a percent of the basal NEFA value.

${ }^{5}$ Values are given as mean \pm SEM.

BFT, and average NEFA concentration in the 2 wk preceding the HEC test, as well as the absolute weight of the different adipose depots (Table 6, Figure 3). The EC50 glucose was positively associated with BCS, BFT, and average NEFA concentration in the 2 wk preceding the HEC test, as well as the absolute weight of the different adipose depots. The proportional distribution of the different adipose depots was not related to the EC50 $0_{\text {glucose }}$ and the $\max _{\text {glucose }}$ (Table 6, Figure 3).

Figure 4 depicts the average values of the \%NEFA and the SSIC together with the fitted dose response curve. The dose response curve of the insulin response of the FA metabolism is determined by the EC50 $0_{\text {NEFA }}$ and the $\min _{\mathrm{NEFA}}$. In the present experiment, the average values of the EC50 $0_{\text {NEFA }}$ and min $_{\text {NEFA }}$ were $19.35 \pm$ $1.48 \mu \mathrm{IU} / \mathrm{mL}$ and $9.87 \pm 0.66 \%$, respectively (Table 5). The decrease in NEFA relative to the basal NEFA concentration $\left(\min _{\mathrm{NEFA}}\right)$ was positively associated with the average NEFA concentration during the 2 wk preceding the HEC test (Table 6, Figure 4). The BCS, BFT, and absolute and proportional amount of the different adipose depots were not significantly associated with the $\mathrm{EC} 50_{\mathrm{NEFA}}$ and the $\mathrm{min}_{\mathrm{NEFA}}$ of the FA metabolism. The mixed linear model revealed that the EC50 $0_{\text {glucose }}$ of the insulin response of the glucose metabolism was significantly larger than the EC50 $0_{\mathrm{NEFA}}$ of the insulin response of the FA metabolism $(P<0.001)$.

\section{DISCUSSION}

The aim of the present study was to determine the influence of the level of fat accumulation on the insulin response of the glucose and FA metabolism in dairy cows. We hypothesized that the insulin response of overconditioned cows may be attenuated. Because overconditioning of dairy cows is mainly a problem in dry dairy cows that can negatively affect early lactation performance (Roche et al., 2013), experiments were conducted on dairy cows at the end of the dry period. Animals in the present study were fed according to their requirements to avoid the influence of over- and underfeeding on the insulin response of the glucose and FA metabolism, as has been demonstrated by Holtenius et al. (2003) and Schoenberg et al. (2012). In the present study, the comparison of BCS and BFT at different

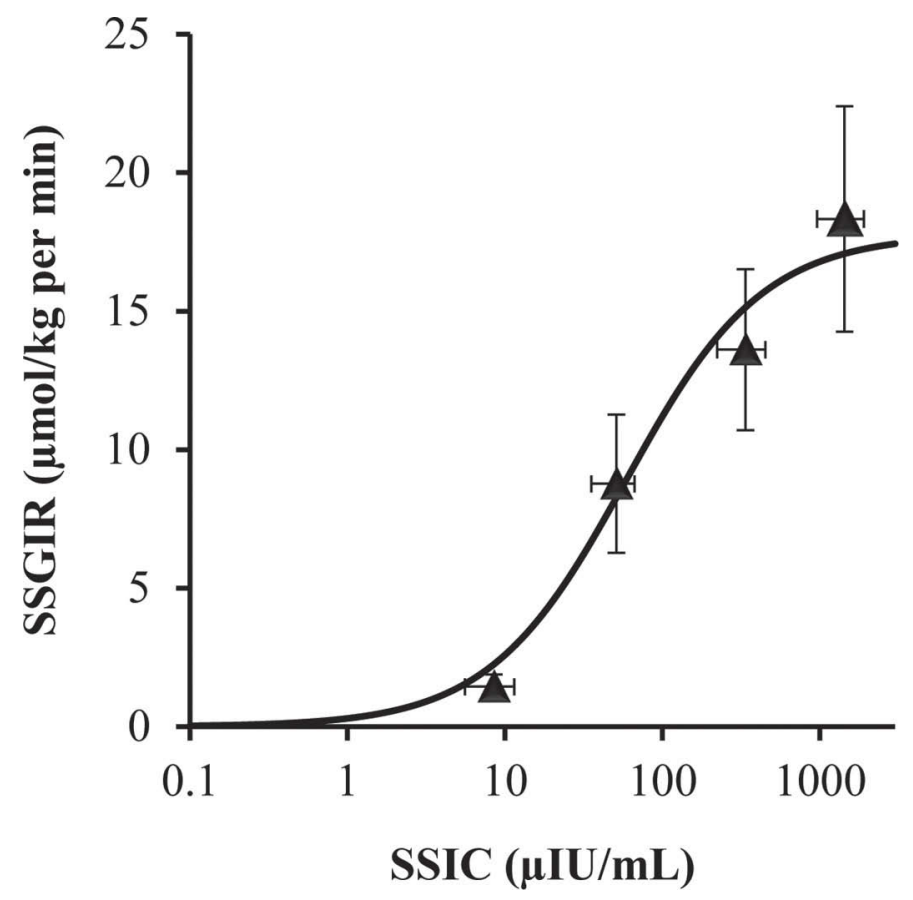

Figure 2. Data points of the experimental animals for the steady state insulin concentration (SSIC) and the steady state glucose infusion rate (SSGIR) during the hyperinsulinemic euglycemic clamp test. Points (ム) represent the means, horizontal error bars represent the SEM SSIC, and vertical error bars represent the SEM SSGIR. The line represents the fitted dose response curve from the nonlinear equation SSGIR $=\frac{\max _{\text {glucose }}}{1+10^{\left(\log E C 50_{\text {glucose }}-\log \text { SSIC }\right)}}$, with $\max _{\text {glucose }}$ being the maximal SSGIR at maximal SSIC and the effective concentration 50 (EC50 glucose $)$ being the insulin concentration needed to achieve half maximal effect. 
Table 5. Model parameters of the dose response curves of the insulin response of the glucose and FA metabolism

\begin{tabular}{llr}
\hline Item & Parameter & Mean \pm SEM \\
\hline Glucose metabolism $^{1}$ & $\max _{\text {glucose }}(\mu \mathrm{mol} / \mathrm{kg}$ per minute $)$ & $18.51 \pm 0.42$ \\
& $\operatorname{EC50}_{\text {glucose }}(\mu \mathrm{IU} / \mathrm{mL})$ & $76.41 \pm 4.46$ \\
FA metabolism $^{2}$ & $\min _{\text {NEFA }}(\%)$ & $9.87 \pm 0.66$ \\
& ${\operatorname{EC} 50_{\text {NEFA }}(\mu \mathrm{IU} / \mathrm{mL})}$ & $19.35 \pm 1.48$ \\
\hline
\end{tabular}

${ }^{1}$ Model parameters of the dose response curve of the glucose metabolism were fitted using the equation: SSGIR $=\frac{\max _{\text {glucose }}}{1+10^{\left(\log E C 50_{\text {glucose }}-\log \text { SSIC }\right)}}$. The shape of the dose response curve is determined by max $_{\text {glcuose }}$ being the maximal steady state glucose infusion rate (SSGIR) at maximal steady state insulin concentration (SSIC) and EC50 $0_{\text {glucose }}$ being the insulin concentration needed to achieve half maximal effect.

${ }^{2}$ Model parameters of the dose response curve of the fatty acid metabolism were fitted using the following equation: $\% \mathrm{NEFA}=\min _{\mathrm{NEFA}}+\frac{1-\min _{\mathrm{NEFA}}}{1+10^{\left(\log \mathrm{SSIC}-\log \mathrm{EC} 50_{\mathrm{NEFA}}\right)}}$. The shape of the dose response curve is determined by $\min _{\text {NEFA }}$ being the minimal NEFA calculated as a percent of basal NEFA at maximal SSIC and EC50 $0_{\text {NEFA }}$ being the insulin concentration needed to achieve half maximal effect.

time points within individuals revealed no significant difference, meaning that the BCS and BFT did not change during the dry period and supporting the fact that no animals were significantly under- or overfed.

Five overconditioned and 4 normally conditioned animals successfully completed our study, in which total body insulin response of the glucose and FA metabolism was determined using the HEC test. The HEC test is the gold standard method to determine the insulin response in humans and animals (DeFronzo et al., 1979). The HEC test allows to determine the total body glucose uptake at supraphysiological concentrations of insulin, thereby giving the possibility to create dose response curves and to determine the insulin concentration needed to elicit half maximal effect (EC50) and the maximal effect of insulin.

\section{Insulin Response of the Glucose Metabolism}

During the HEC test, the SSGIR reflects the insulinmediated increase in total body glucose metabolism and is the result of both the decrease in endogenous glucose production and the increase in glucose uptake by skeletal muscle and adipose tissue (DeFronzo et al., 1979). Skeletal muscle is the most important contributor to this glucose uptake. As such, the insulin response of the glucose metabolism during the HEC test reflects mainly the insulin response of skeletal muscle (DeFronzo and Tripathy, 2009). The most important finding of the present study is that the insulin response of the glucose metabolism in dry dairy cows is negatively associated with excessive accumulation of adipose tissue. This impaired insulin action in overconditioned dairy

Table 6. Estimates (regression coefficient $\pm \mathrm{SE}$ ) of the univariate regression models describing the relationship between animal characteristics and depot weights with the parameters of the insulin dose response curves of the glucose and FA metabolism

\begin{tabular}{|c|c|c|c|c|}
\hline \multirow[b]{2}{*}{ Item } & \multicolumn{2}{|c|}{ Glucose metabolism } & \multicolumn{2}{|c|}{ FA metabolism } \\
\hline & $\begin{array}{c}\max _{\text {glucose }} \\
(\mu \mathrm{mol} / \mathrm{kg} \text { per } \min )\end{array}$ & $\begin{array}{l}\text { EC50 } 0_{\text {glucose }} \\
(\mu \mathrm{IU} / \mathrm{mL})\end{array}$ & $\underset{(\%)}{\min _{\text {NEFA }}}$ & $\begin{array}{l}\text { EC50 } 0_{\text {NEFA }} \\
(\mu \mathrm{IU} / \mathrm{mL})\end{array}$ \\
\hline $\mathrm{BFT}^{1}(\mathrm{~cm})$ & $-2.52 \pm 0.81^{*}$ & $14.16 \pm 3.75^{* *}$ & $0.025 \pm 0.017$ & $-4.20 \pm 4.09$ \\
\hline $\mathrm{NEFA}^{2}(\mathrm{mmol} / \mathrm{L})$ & $-14.77 \pm 5.92^{*}$ & $93.42 \pm 25.39^{*}$ & $0.27 \pm 0.08^{*}$ & $-19.97 \pm 27.53$ \\
\hline Total body fat (kg) & $-0.10 \pm 0.03^{* *}$ & $0.53 \pm 0.13^{* *}$ & $0.00090 \pm 0.00063$ & $-0.16 \pm 0.15$ \\
\hline Pelvic fat $(\mathrm{kg})$ & $-1.93 \pm 0.44^{* *}$ & $9.22 \pm 2.85^{*}$ & $0.015 \pm 0.012$ & $-1.91 \pm 2.89$ \\
\hline Thoracal fat (kg) & $-1.15 \pm 0.38^{*}$ & $5.52 \pm 2.24^{*}$ & $0.0068 \pm 0.0087$ & $-1.82 \pm 1.90$ \\
\hline Abdominal $\mathrm{fat}^{3}(\%)$ & $-11.37 \pm 42.23$ & $180.89 \pm 223.46$ & $0.79 \pm 0.59$ & $-145.84 \pm 138.42$ \\
\hline Subcutaneous fat ${ }^{3}(\%)$ & $-46.48 \pm 63.16$ & $179.64 \pm 358.74$ & $-0.16 \pm 1.03$ & $145.66 \pm 223.37$ \\
\hline Pelvic fat ${ }^{3}(\%)$ & $83.52 \pm 118.29$ & $-663.67 \pm 626.88$ & $-1.38 \pm 1.85$ & $479.34 \pm 389.58$ \\
\hline Thoracal fat ${ }^{3}(\%)$ & $78.08 \pm 76.72$ & $-662.50 \pm 367.43$ & $-2.13 \pm 1.01$ & $101.64 \pm 285.92$ \\
\hline
\end{tabular}

\footnotetext{
${ }^{1}$ Backfat thickness.

${ }^{2}$ Serum NEFA concentration.

${ }^{3}$ Depot weight calculated as percentage of total body fat.

${ }^{*} P<0.05 ; * * P<0.01$.
} 


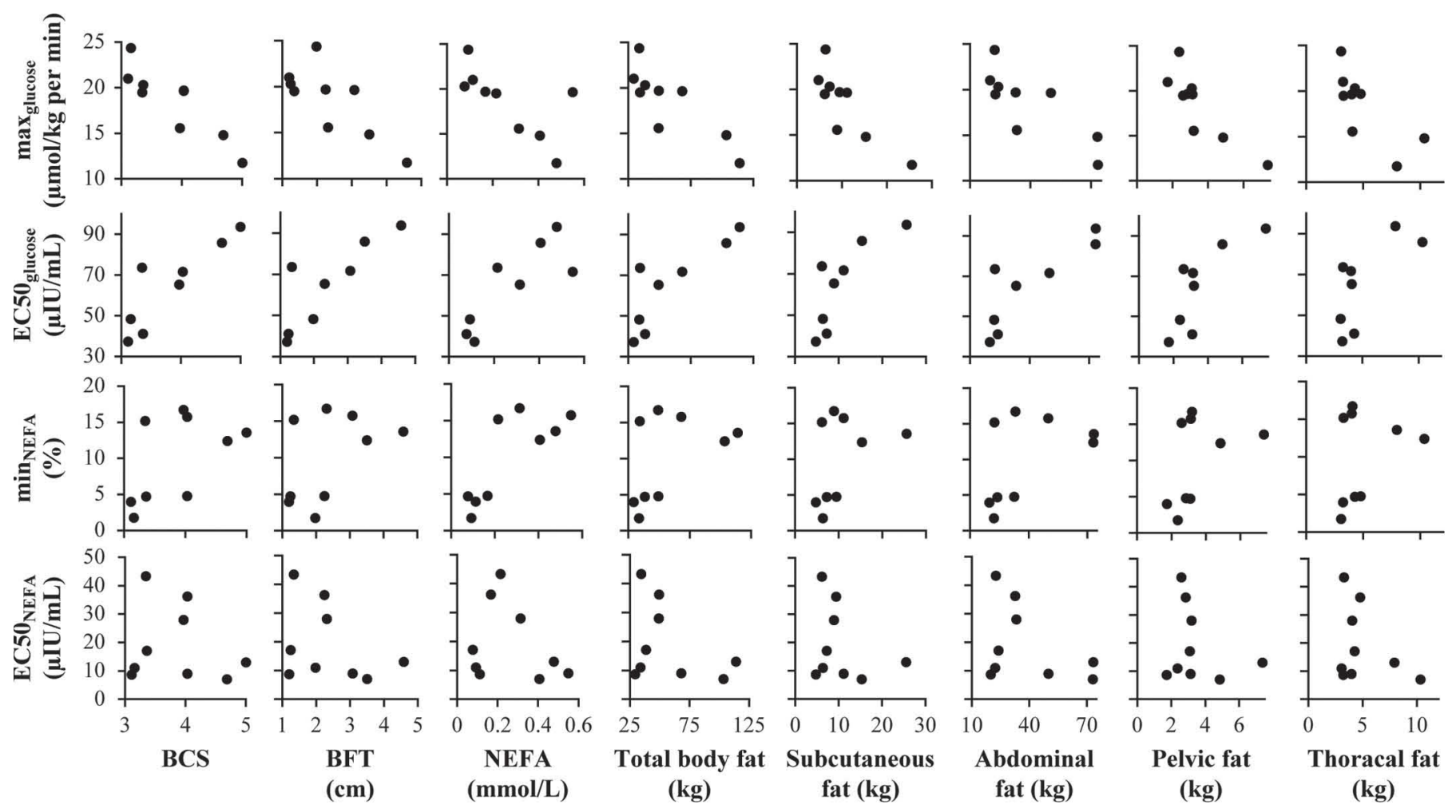

Figure 3. Visualization of the relationship between the parameters derived from the dose response curves of the glucose and FA metabolism and the different variables representing the level of fat accumulation in the experimental animals. Points $(\bullet)$ represent the observations of the individual animals. Max glucose $_{\text {and }}$ min $_{\text {NEFA }}$ represent the maximal insulin response of the glucose and NEFA metabolism, respectively. EC50 $0_{\text {glucose }}$ and EC50 $0_{\mathrm{NEFA}}$ represent the insulin concentration needed to achieve the half maximal effect of the glucose and NEFA metabolism, respectively; $\mathrm{BFT}=$ backfat thickness.

cows is characterized by an increased EC50 glucose and a decreased maximal effect of insulin $\left(\max _{\text {glucose }}\right)$ and can be described as decreased insulin sensitivity and decreased insulin responsiveness, respectively (Kahn, 1978).

Impaired insulin action in obese sheep and obese heifers has been demonstrated (McCann and Reimers, 1985; Bergman et al., 1989); however, this impaired insulin action was only characterized by decreased insulin sensitivity, whereas the insulin responsiveness remained unchanged. The difference with our findings may be explained by differences in the experimental setup and by the fact that in our study animals were in the last month of gestation, a period in which homeorhetic adaptations may modulate the insulin response of the glucose metabolism (Bell and Bauman, 1997).

The obtained values for EC50 $0_{\text {glucose }}$ and maximum SSGIR ( $\left.\max _{\text {glucose }}\right)$ of the glucose metabolism in the present study are comparable with experiments performed in sheep (Janes et al., 1985; Bergman et al., 1989; Petterson et al., 1993). As expected, the maximum SSGIR was lower compared with lactating cows (Kusenda et al., 2013). The difference between the maximum SSGIR in dry and lactating cows can be explained by the high insulin-independent glucose uptake of the lactating mammary gland. Indeed, glucose uptake by the mammary gland at 14 DIM increases total glucose requirements when compared with the dry period (De Koster and Opsomer, 2013).

\section{Insulin Response of the FA Metabolism}

During the HEC test, the decrease of the SSNEFA compared with basal NEFA level reflects the inhibitory effect of insulin on the circulating NEFA. This is achieved by the combined effect of insulin to inhibit lipolysis and to stimulate lipogenesis (Campbell et al., 1992; Frayn et al., 1997). Obtained values for the EC50 $0_{\text {NEFA }}$ and minimal \% NEFA $\left(\min _{\text {NEFA }}\right)$ of the FA metabolism are comparable with similar experiments performed in sheep (Petterson et al., 1994) and lactating dairy cows (Kusenda et al., 2013). The insulin action at the level of the FA metabolism was not associated with the amount of accumulated adipose tissue. Similarly, overfeeding dairy cows during the dry period did not impair insulin signaling in subcutaneous adipocytes (Ji et al., 2012). 
Differences in the regulatory mechanisms of insulin between the glucose and FA metabolism are known to occur in humans (Arner et al., 1984) and have recently been demonstrated in dry dairy cows as well (Schoenberg et al., 2012). The present findings suggest specific pathways by which excessive accumulation of fat impairs insulin response of the glucose metabolism without altering insulin response of the FA metabolism in dry dairy cows. It has been reported that skeletal muscle insulin resistance may develop in the absence of insulin resistance of the adipose tissue (Crettaz and Jeanrenaud, 1980; Kahn and Flier, 2000). In the present study, only the insulin response of the glucose metabolism is decreased, reflecting reduced insulin response of the glucose uptake by skeletal muscle. A drawback of the difference in insulin response between the glucose and FA metabolism is that results obtained based on the glucose metabolism may not be extrapolated as such to the FA metabolism.

\section{Comparison Between the Insulin Response of the Glucose and FA Metabolism}

Comparison of EC50 between the glucose and FA metabolism revealed lower insulin sensitivity of the glucose metabolism compared with the FA metabolism in the same individual, which is in agreement with observations in pregnant sheep (Petterson et al., 1993; 1994). This observation implies that the antilipolytic effect of insulin occurs at much lower insulin concentrations compared with the stimulatory effect of insulin on the glucose transport (Kahn and Flier, 2000). Similarly, Vernon (2005) described different levels of insulin sensitivity for different metabolic processes; anabolic processes (glycogen, protein, and triacylglycerol synthesis) and peripheral glucose uptake are less sensitive to insulin compared with catabolic processes such as lipolysis and proteolysis. From the perspective of treating cows that mobilize excessive amounts of NEFA in the periparturient period, this distinction between the glucose and FA metabolism may be favorable. Because treatment is based on inhibition of lipolysis by increasing circulating concentrations of glucose and insulin, and the action of insulin at the level of the FA metabolism remains intact in overconditioned cows. Additionally, the half maximal effect of insulin on the FA metabolism is achieved at low levels of insulin, which are easily reached by intravenous infusion of a glucose solution (Holtenius et al., 2003) and peroral bolus administration of glucogenic precursors (Nielsen and Ingvartsen, 2004). Present observations support current treatment protocols, although care has to be taken when extrapolating observations from dry to lactating cows.

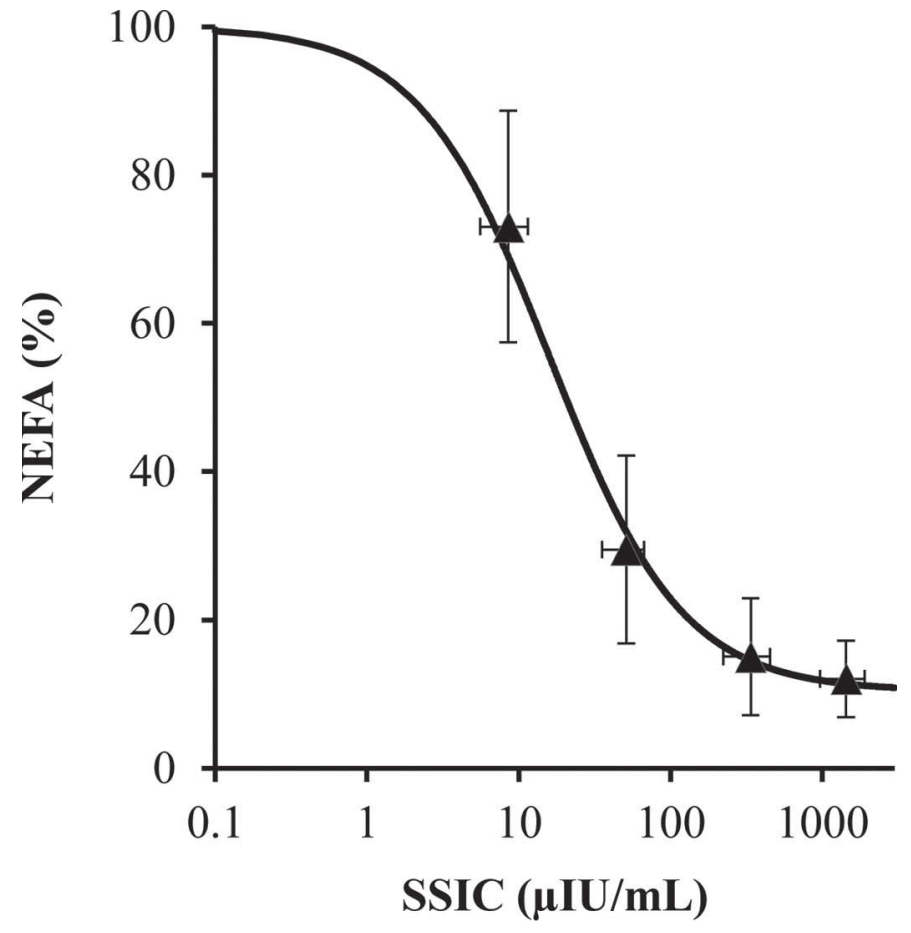

Figure 4. Data points of the experimental animals for the steady state insulin concentration (SSIC) and the procentual NEFA level compared with basal (\%NEFA) during the hyperinsulinemic euglycemic clamp test. Points $(\boldsymbol{\Lambda})$ represent the means, horizontal error bars represent the SEM SSIC, and vertical error bars represent the SEM \%NEFA. The line represents the fitted dose response curve from the nonlinear equation $\% \mathrm{NEFA}=\min _{\mathrm{NEFA}}+\frac{1-\min _{\mathrm{NEFA}}}{1+10^{\left(\log \mathrm{SSIC}-\log \mathrm{EC} 50_{\mathrm{NEFA}}\right)}}$, with $\min _{\text {NEFA }}$ being the minimal steady state NEFA at maximal SSIC and the effective concentration 50 (EC50 $0_{\mathrm{NEFA}}$ ) being the insulin concentration needed to achieve half maximal effect.

\section{Role of NEFA and Insulin in the Insulin Response of the Glucose and FA Metabolism}

Impairment of insulin action associated with obesity can be explained by hyperinsulinemia, increased concentration of circulating NEFA, and altered production of adipokines. Hyperinsulinemia causes downregulation of the number of insulin receptors in adipose tissue, skeletal muscle, and liver, thereby inducing a state of decreased insulin sensitivity (Crettaz and Jeanrenaud, 1980; DeFronzo and Tripathy, 2009). Overfeeding dairy cows during the dry period is associated with hyperinsulinemia and insulin resistance (Holtenius et al., 2003). However, in the present research, overconditioning was not associated with a state of hyperinsulinemia, as indicated by the nonsignificant correlation between basal insulin concentration at the start of the HEC test and BFT and BCS. Serum insulin levels start to decline in the last month before parturition (Accorsi et al., 2005; Kokkonen et al., 2005) due to the increased glucose 
requirements of the gravid uterus and the developing mammary gland (Bauman and Currie, 1980; Bell et al., 1995). As such, the stimuli to the pancreas to secrete insulin are decreased, when cows are fed according to their requirements. Homeorhetic mechanisms in periparturient dairy cows probably overrule the effect of obesity on hyperinsulinemia, and different mechanisms may be responsible for the development of insulin resistance between overconditioned and overfed cows.

As expected, cows with high BCS and BFT had also higher concentrations of circulating NEFA during the weeks preceding HEC tests, indicating precalving mobilization of body fat (Grummer, 1993; Kokkonen et al., 2005). High levels of circulating NEFA are known to negatively affect the effect of insulin at the level of the glucose and FA metabolism, as demonstrated experimentally in dairy cows by intravenous infusion of tallow emulsion (Pires et al., 2007; Salin et al., 2012) and by prolonged fasting (Oikawa and Oetzel, 2006), whereas in early lactation NEFA level is negatively associated with glucose decrease after insulin injection (Kerestes et al., 2009). Similarly, in the present research, impaired insulin action at the level of the glucose metabolism $\left(\mathrm{EC} 50_{\text {glucose }}\right.$ and $\left.\max _{\text {glucose }}\right)$ and the FA metabolism $\left(\min _{\text {NEFA }}\right)$ was associated with high levels of NEFA in the weeks preceding the HEC test. Although statistically significant, it is questionable if the effect of NEFA on the minimum \%NEFA is biologically relevant, because estimates of the regression function are much lower compared with estimates of the regression function of the glucose metabolism. Nonesterified FA are shown to induce serine phosphorylation of IRS1, an important protein in the intracellular signaling cascade of insulin (Le Marchand-Brustel et al., 2003). Serine phosphorylation of IRS reduces insulin induced tyrosine phosphorylation of proteins thereby decreasing activation of the intracellular insulin signaling cascade (Shulman, 2000; Le Marchand-Brustel et al., 2003).

Additional factors which may influence insulin response are bioactive molecules produced by the adipose tissue, called adipokines. In human medicine, the metabolic syndrome is known as a condition which links obesity, cardiovascular disease, dyslipidemia, insulin resistance, and type II diabetes mellitus (Cornier et al., 2008). Dysregulated production of adipokines by the obese adipose tissue plays an important role in the development of insulin resistance in an endocrine, paracrine, or autocrine way. This dysregulated production is characterized by an increased production of proinflammatory adipokines, such as tumor necrosis factor- $\alpha$, resistin, IL6, and decreased production of adiponectin, an anti-inflammatory adipokine (Cornier et al., 2008). Recent investigations support an important role for resistin (Reverchon et al., 2014), adiponectin (Singh et al., 2014), tumor necrosis factor- $\alpha$ (Ohtsuka et al., 2001), and leptin (Ingvartsen and Boisclair, 2001) in the transition period of dairy cows. However, the underlying mechanism by which adipokines of enlarged adipocytes in overconditioned dairy cattle may influence insulin response of the glucose and FA metabolism requires further investigation.

\section{Role of Adipose Tissue Distribution in the Insulin Response of the Glucose and FA Metabolism}

Excessive accumulation of visceral fat is an important factor in the development of insulin resistance in human medicine. The metabolic activity (release of NEFA and adipokines) and the location (direct draining to the liver) makes overaccumulation of fat in the abdominal adipose tissue more detrimental compared with subcutaneous adipose tissue (Wajchenberg, 2000). In the present study, the absolute amount of fat present in the body, in particular, was demonstrated to be negatively associated with the insulin response of the glucose metabolism, whereas measures of body fat distribution (proportional distribution) were not associated with the insulin response of the glucose or FA metabolism. However, limited variability existed in the distribution of body fat among the different adipose depots. Therefore it seems that an increase in BCS in the present study was associated with an increase in absolute weight of all fat depots and, proportionally, all fat depots gained similar amounts of weight. Adipose tissue metabolism differs among the different adipose depots. The latter is a species-specific phenomenon and some interindividual variability exists within a species (Pond, 1992). In dairy cows, it has been demonstrated that overfeeding may increase abdominal fat depots without a visible increase of subcutaneous adipose tissue (Drackley et al., 2014). Whereas in the immediate postpartum period there are cows with a normal amount of subcutaneous fat (normal BCS) but a considerable amount of omental fat (high omental fat score; Hostens et al., 2012). These studies suggest variation in adipose tissue metabolism according to the location in the body of dairy cows. More research is needed to identify the potential role of the different adipose depots in the development of insulin resistance in dairy cows and the potential mechanisms by which the different adipose depots may influence health disorders in dairy cows.

\section{CONCLUSIONS}

The present research demonstrates a negative association between the level of fat accumulation and the 
insulin response of the glucose metabolism in pregnant dairy cows at the end of the dry period. This impaired insulin action at the level of the glucose metabolism is characterized by both decreased insulin sensitivity as well as decreased insulin responsiveness. Insulin response of the FA metabolism, on the other hand, was not associated with the level of fat accumulation. Distinction between the insulin response of the glucose and the FA metabolism was also obvious for the insulin concentration needed to elicit half maximal effect. For FA metabolism, the half maximal effect was reached at lower insulin concentrations compared with the glucose metabolism.

\section{ACKNOWLEDGMENTS}

This research was funded by the Special Research Fund of Ghent University, grant number 01D28410. The authors wish to thank Isabel Lemahieu and Petra Van Damme for excellent technical assistance in the lab.

\section{REFERENCES}

Accorsi, P. A., N. Govoni, R. Gaiani, C. Pezzi, E. Seren, and C. Tamanini. 2005. Leptin, GH, PRL, insulin and metabolic parameters throughout the dry period and lactation in dairy cows. Reprod. Domest. Anim. 40:217-223.

Arner, P., J. Bolinder, P. Engfeldt, J. Hellmer, and J. Ostman. 1984. Influence of obesity on the antilipolytic effect of insulin in isolated human fat-cells obtained before and after glucose-ingestion. J. Clin. Invest. 73:673-680.

Bauman, D. E., and W. B. Currie. 1980. Partitioning of nutrients during pregnancy and lactation-A review of mechanisms involving homeostasis and homeorhesis. J. Dairy Sci. 63:1514-1529.

Bell, A. W., and D. E. Bauman. 1997. Adaptations of glucose metabolism during pregnancy and lactation. J. Mammary Gland Biol. Neoplasia 2:265-278.

Bell, A. W., R. Slepetis, and R. A. Ehrhardt. 1995. Growth and accretion of energy and protein in the gravid uterus during late pregnancy in Holstein cows. J. Dairy Sci. 78:1954-1961.

Bergman, E. N., S. S. Reulein, and R. E. Corlett. 1989. Effects of obesity on insulin sensitivity and responsiveness in sheep. Am. J. Physiol. 257:E772-E781.

Campbell, P. J., M. G. Carlson, J. O. Hill, and N. Nurjhan. 1992. Regulation of free fatty-acid metabolism by insulin in humans - role of lipolysis and reesterification. Am. J. Physiol. 263:E1063-E1069.

Cornier, M. A., D. Dabelea, T. L. Hernandez, R. C. Lindstrom, A. J. Steig, N. R. Stob, R. E. Van Pelt, H. Wang, and R. H. Eckel. 2008. The metabolic syndrome. Endocr. Rev. 29:777-822.

Crettaz, M., and B. Jeanrenaud. 1980. Postreceptor alterations in the states of insulin resistance. Metabolism 29:467-473.

De Koster, J. D., and G. Opsomer. 2013. Insulin resistance in dairy cows. Vet. Clin. North Am. Food Anim. Pract. 29:299-322.

DeFronzo, R. A., J. D. Tobin, and R. Andres. 1979. Glucose clamp technique-Method for quantifying insulin-secretion and resistance. Am. J. Physiol. 237:E214-E223.

DeFronzo, R. A., and D. Tripathy. 2009. Skeletal muscle insulin resistance is the primary defect in type 2 diabetes. Diabetes Care 32:S157-S163.

Drackley, J. K., R. L. Wallace, D. Graugnard, J. Vasquez, B. F. Richards, and J. J. Loor. 2014. Visceral adipose tissue mass in nonlactating dairy cows fed diets differing in energy density. J. Dairy Sci. 97:3420-3430.
Edmonson, A. J., I. J. Lean, L. D. Weaver, T. Farver, and G. Webster. 1989. A body condition scoring chart for Holstein dairy-cows. J. Dairy Sci. 72:68-78.

Frayn, K. N., B. A. Fielding, and L. K. M. Summers. 1997. Investigation of human adipose tissue metabolism in vivo. J. Endocrinol. 155:187-189.

Grummer, R. R. 1993. Etiology of lipid-related metabolic disorders in periparturient dairy-cows. J. Dairy Sci. 76:3882-3896.

Grummer, R. R., D. G. Mashek, and A. Hayirli. 2004. Dry matter intake and energy balance in the transition period. Vet. Clin. North Am. Food Anim. Pract. 20:447-470.

Holtenius, K., S. Agenas, C. Delavaud, and Y. Chilliard. 2003. Effects of feeding intensity during the dry period. 2. Metabolic and hormonal responses. J. Dairy Sci. 86:883-891.

Holtenius, P., and K. Holtenius. 2007. A model to estimate insulin sensitivity in dairy cows. Acta Vet. Scand. 49:29.

Hostens, M., V. Fievez, J. L. M. R. Leroy, J. Van Ranst, B. Vlaeminck, and G. Opsomer. 2012. The fatty acid profile of subcutaneous and abdominal fat in dairy cows with left displacement of the abomasum. J. Dairy Sci. 95:3756-3765.

Ingvartsen, K. L., and Y. R. Boisclair. 2001. Leptin and the regulation of food intake, energy homeostasis and immunity with special focus on periparturient ruminants. Domest. Anim. Endocrinol. $21: 215-250$.

Janes, A. N., T. E. Weekes, and D. G. Armstrong. 1985. Insulin action and glucose metabolism in sheep fed on dried-grass or ground, maize-based diets. Br. J. Nutr. 54:459-471.

Ji, P., J. S. Osorio, J. K. Drackley, and J. J. Loor. 2012. Overfeeding a moderate energy diet prepartum does not impair bovine subcutaneous adipose tissue insulin signal transduction and induces marked changes in peripartal gene network expression. J. Dairy Sci. 95:4333-4351.

Kahn, B. B., and J. S. Flier. 2000. Obesity and insulin resistance. J. Clin. Invest. 106:473-481.

Kahn, C. R. 1978. Insulin resistance, insulin insensitivity, and insulin unresponsiveness: A necessary distinction. Metabolism 27(Suppl 2):1893-1902.

Kerestes, M., V. Faigl, M. Kulcsar, O. Balogh, J. Foldi, H. Febel, Y. Chilliard, and G. Huszenicza. 2009. Periparturient insulin secretion and whole-body insulin responsiveness in dairy cows showing various forms of ketone pattern with or without puerperal metritis. Domest. Anim. Endocrinol. 37:250-261.

Kokkonen, T., J. Taponen, T. Anttila, L. Syrjala-Qvist, C. Delavaud, Y. Chilliard, M. Tuori, and A. T. Tesfa. 2005. Effect of body fatness and glucogenic supplement on lipid and protein mobilization and plasma leptin in dairy cows. J. Dairy Sci. 88:1127-1141.

Kusenda, M., M. Kaske, M. Piechotta, L. Locher, A. Starke, K. Huber, and J. Rehage. 2013. Effects of dexamethasone-21-isonicotinate on peripheral insulin action in dairy cows 5 days after surgical correction of abomasal displacement. J. Vet. Intern. Med. 27:200-206.

Le Marchand-Brustel, Y., P. Gual, T. Gremeaux, T. Gonzalez, R. Barres, and J. Tanti. 2003. Fatty acid-induced insulin resistance: Role of insulin receptor substrate 1 serine phosphorylation in the retroregulation of insulin signaling. Biochem. Soc. Trans. 31:1152-1156.

McCann, J. P., and T. J. Reimers. 1985. Glucose response to exogenous insulin and kinetics of insulin metabolism in obese and lean heifers. J. Anim. Sci. 61:612-618.

Morrow, D. A. 1976. Fat cow syndrome. J. Dairy Sci. 59:1625-1629.

Motulsky, H., and A. Christopoulos. 2004. Fitting Models to Biological Data Using Linear and Nonlinear Regression: A Practical Guide to Curve Fitting. Oxford University Press, San Diego, CA.

Nielsen, N. I., and K. L. Ingvartsen. 2004. Propylene glycol for dairy cows: A review of the metabolism of propylene glycol and its effects on physiological parameters, feed intake, milk production and risk of ketosis. Anim. Feed Sci. Technol. 115:191-213.

NRC. 2001. Nutrient Requirements of Dairy Cattle. 7th rev. ed. Natl. Acad. Press., Washington, DC.

Ohtsuka, H., M. Koiwa, A. Hatsugaya, K. Kudo, F. Hoshi, N. Itoh, H. Yokota, H. Okada, and S. Kawamura. 2001. Relationship between serum TNF activity and insulin resistance in dairy cows 
affected with naturally occurring fatty liver. J. Vet. Med. Sci. 63:1021-1025.

Oikawa, S., and G. R. Oetzel. 2006. Decreased insulin response in dairy cows following a four-day fast to induce hepatic lipidosis. J. Dairy Sci. 89:2999-3005.

Petterson, J. A., F. R. Dunshea, R. A. Ehrhardt, and A. W. Bell. 1993. Pregnancy and undernutrition alter glucose metabolic responses to insulin in sheep. J. Nutr. 123:1286-1295.

Petterson, J. A., R. Slepetis, R. A. Ehrhardt, F. R. Dunshea, and A. W. Bell. 1994. Pregnancy but not moderate undernutrition attenuates insulin suppression of fat mobilization in sheep. J. Nutr. 124:2431-2436.

Pires, J. A., A. H. Souza, and R. R. Grummer. 2007. Induction of hyperlipidemia by intravenous infusion of tallow emulsion causes insulin resistance in Holstein cows. J. Dairy Sci. 90:2735-2744.

Pond, C. M. 1992. An evolutionary and functional view of mammalian adipose-tissue. Proc. Nutr. Soc. 51:367-377.

Reverchon, M., C. Rame, J. Cognie, E. Briant, S. Elis, D. Guillaume, and J. Dupont. 2014. Resistin in dairy cows: Plasma concentrations during early lactation, expression and potential role in adipose tissue. PLoS ONE 9:e93198.

Roche, J. R., J. K. Kay, N. C. Friggens, J. J. Loor, and D. P. Berry. 2013. Assessing and managing body condition score for the prevention of metabolic disease in dairy cows. Vet. Clin. North Am. Food Anim. Pract. 29:323-336.

Rukkwamsuk, T., T. A. M. Kruip, and T. Wensing. 1999. Relationship between overfeeding and overconditioning in the dry period and the problems of high producing dairy cows during the postparturient period. Vet. Q. 21:71-77.
Rukkwamsuk, T., T. Wensing, and M. J. H. Geelen. 1998. Effect of overfeeding during the dry period on regulation of adipose tissue metabolism in dairy cows during the periparturient period. J. Dairy Sci. 81:2904-2911.

Salin, S., J. Taponen, K. Elo, I. Simpura, A. Vanhatalo, R. Boston, and T. Kokkonen. 2012. Effects of abomasal infusion of tallow or camelina oil on responses to glucose and insulin in dairy cows during late pregnancy. J. Dairy Sci. 95:3812-3825.

Schoenberg, K. M., R. M. Ehrhardt, and T. R. Overton. 2012. Effects of plane of nutrition and feed deprivation on insulin responses in dairy cattle during late gestation. J. Dairy Sci. 95:670-682.

Schröder, U. J., and R. Staufenbiel. 2006. Invited review: Methods to determine body fat reserves in the dairy cow with special regard to ultrasonographic measurement of backfat thickness. J. Dairy Sci. 89:1-14.

Shulman, G. I. 2000. Cellular mechanisms of insulin resistance. J. Clin. Invest. 106:171-176.

Singh, S. P., S. Haussler, J. F. L. Heinz, S. H. Akter, B. Saremi, U. Muller, J. Rehage, S. Danicke, M. Mielenz, and H. Sauerwein. 2014. Lactation driven dynamics of adiponectin supply from different fat depots to circulation in cows. Domest. Anim. Endocrinol. 47:35-46.

Vernon, R. G. 2005. Metabolic regulation. Pages 443-468 in Quantitative Aspects of Ruminant Digestion and Metabolism. J. Dijkstra, J. M. Forbes, and J. France, ed. CAB International Wallingford, UK.

Wajchenberg, B. L. 2000. Subcutaneous and visceral adipose tissue: Their relation to the metabolic syndrome. Endocr. Rev. 21:697738. 